\title{
AREAS PRONE TO LAND SUBSIDENCE AND THEIR EVOLUTIONS IN BELGIUM DURING THE LAST 30 YEARS
}

\author{
Pierre-Yves Declercq ${ }^{1}$, Atefe Choopani ${ }^{1,2}$, Alain Dassargues $^{2}$, Xavier Devleeschouwer $^{1}$ \\ ${ }^{1}$ Royal Belgium Institute of Natural Sciences, Geological Survey of Belgium, Rue Jenner 13, 1000 \\ Brussels, ${ }^{2}$ Liège University, Hydrogeology \& Environmental Geology, Urban \& Environmental \\ Engineering, allée de la Découverte 9, 4000 Liège
}

\begin{abstract}
PSInSAR analyses across Belgium using ERS 1-2, ENVISAT, TerraSAR-X and Sentinel 1 allowed to follow several ground movements areas during the last three decades. Several areas of regional importance are affected by land subsidence processes that have been observed during this period (i.e. the alluvial plain of the Schelde estuary in Antwerpen, a large area in the West Flanders province and one around Merchtem area). Other land subsidence areas associated to old coal mining both in Flanders (Campine basin) and Wallonia (Hainaut and Liège province) are affected by progressive uplifting conditions linked to the mining aquifer piezometric rebound. It is extremely important to follow the spatio-temporal behavior of these phenomena to forecast their influences and their effects on the urban developments.
\end{abstract}

Index Terms - Land subsidence, PSInSAR technique, long-term ground movements, aquifer rebound.

\section{INTRODUCTION}

Ground movements and particularly land subsidence are of key concern in terms of geological hazard management for the responsible authorities. In China, the city of Shanghai is affected by land subsidence since 1920 [1] with an average subsidence rate of $28 \mathrm{~mm} /$ year since 1976. In 2007, the estimated economic loss due to structural damage to buildings for the city of Shanghai is estimated at 13 billion US\$ [2]. In Mexico City, the subsidence rate related to groundwater extraction amounts up to $35 \mathrm{~cm} /$ year during the 1990s and 2000s [3]. During the 2003-2010 period of time, the average rate of land subsidence was estimated between 7 to $8 \mathrm{~cm} /$ year [4]. The processing of Sentinel 1 images covering the period 2014-2020 permitted to highlight subsidence peaks of vertical velocities reaching $38 \mathrm{~cm} /$ year in some districts of the city [5]. In Belgium, the Persistent Scatterer Interferometry (PSInSAR) [6] was applied to measure the ground movements. This permitted to highlight land subsidence or uplifting ground deformations, which have been deciphered and followed through years with a millimetric precision by using the different generation of
Synthetic Aperture Radar (SAR) satellites giving more than 870 images for processing. The approach provided insights regarding the time scale, the amplitude and spatial distribution of these ground surface elevation or subsidence movements. Knowledge of the local hydrogeological and geological conditions together with the precise location of the ground movements will allow to better discriminate the different factors contributing to those movements.

The main objectives of the LASUGEO (monitoring LAnd SUbsidence caused by Groundwater exploitation through gEOdetic measurements financed by the Belgian Science Policy) project are associated to the groundwater exploitation that has hitherto provoked unforeseen land surface movements (subsidence sometimes followed by a rebound during the aquifer piezometric rebound). These land surface movements need to be mapped and quantified by comparing hydrogeological models to different geodetic techniques using long time series. This paper presents the first PSInSAR processing results of the project covering a selection of test cases in Belgium.

\section{DATA AND METHOD}

To monitor the long-term ground movements, we analysed a total of 877 SAR images from 1992 to 2020 (Table 1) using the PSInSAR technique. It involves the simultaneous processing of a stack of multiple SAR images covering the same Region Of Interest (ROI) allowing the correction of uncorrelated phase noises. PSInSAR. identifies pixels that have a good correlation and stable phases during a long period of time in the stack of interferograms [6], [7]. The final results consist of a large set of geo-localised points called Persistent Scatterer (PS) for which the timeseries of deformation based on a reference point is calculated for each satellite images as well as the average rate of deformation. The PSInSAR analyses have been achieved using mainly two software suites: the ERS, ENVISAT and TerraSAR-X data were processed using Doris-StaMPS [8] while the recent Sentinel 1 data were done using SNAP-StaMPS. During the processing, the external digital elevation model (DEM) data from the Shuttle Radar Topography Mission (SRTM 3-arc second) with $90 \mathrm{~m}$ horizontal resolution [9] was used to eliminate the topographic component of the interferometric 
phase. The large temporal data availability allowed us to explore the long-term ground movements of millimetric amplitude of the subsidence in Antwerp, in West-Flanders, in Merchtem and in the coal mines basins in Flanders and Wallonia. The annual average velocity of the PS for ENVISAT covering Belgium is shown in the Figure 1. The PSInSAR data were compared with the time series of the available GNSS data located in the ROI.

\begin{tabular}{|c|c|c|c|}
\hline $\mathrm{T}$ & Sat & N of images & Period \\
\hline 380 & ERS & 62 & $1992-2000$ \\
\hline 423 & ERS & 67 & $1992-2001$ \\
\hline 466 & ERS & 77 & $1992-2006$ \\
\hline 380 & ENVISAT & 60 & $2003-2010$ \\
\hline 423 & ENVISAT & 74 & $2003-2010$ \\
\hline 466 & ENVISAT & 48 & $2003-2010$ \\
\hline 166 & S1 & 98 & $2017-2020$ \\
\hline 157 & S1 & 102 & $2016-2020$ \\
\hline 161 & S1 & 129 & $2017-2020$ \\
\hline 163 & S1 & 110 & $14 / 06 / 2017$ \\
\hline 48 & TSX & 50 & $2017-2020$ \\
\hline
\end{tabular}

Table 1: Characteristics of the SAR image datasets giving the satellite, the track number, the number of SAR images and the time interval. Track (T), Satellite (Sat), Number of images ( $\mathrm{N}$ of images) and time interval (Period) covered are given.

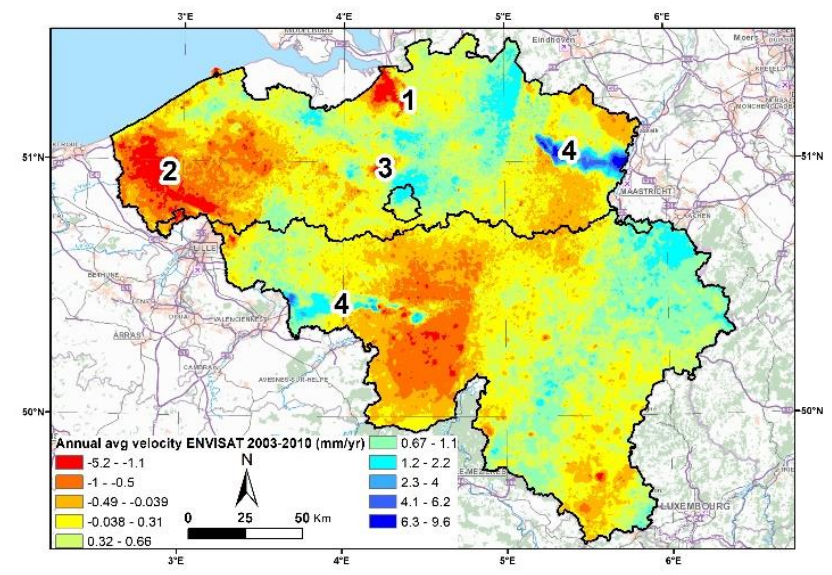

Figure 1: PSInSAR annual average velocity during ENVISAT (2003-2010) in $\mathrm{mm} / \mathrm{yr}$. 1. Antwerp, 2. WestFlanders Province, 3. Merchtem and 4. Limburg and Hainaut coal mines.

\subsection{Antwerp harbour}

\section{RESULTS}

The land subsidence process is highlighted by an annual average Line of Sight (LOS) velocity of about $-3.4 \mathrm{~mm} / \mathrm{year}$ during the years 1992-2001 (ERS1/2 datasets), followed by an annual average LOS velocity of about $-2.71 \mathrm{~mm} /$ year and $-2.11 \mathrm{~mm} /$ year respectively during the years 2003-2010 (ENVISAT) and 2016-2019 (Sentinel 1) [10]. The PS measurements during the S1 time interval are illustrating the ground motions in the region of Antwerp (Figure 2). The harbour $(\mathrm{H})$ situated in estuarine conditions of the Scheldt River characterised by Holocene alluvial sediments is opposed to the city centre of Antwerp (Ant) where Neogene sediments are directly found. The PS velocities measured in the city centre of Antwerp, show that the city is not affected by the subsidence observed in the alluvial plain nearby. In the harbour, the main settlement seems to be due to the consolidation of the Scheldt alluvial deposits in the harbour under the weight of landfills and heavy buildings.

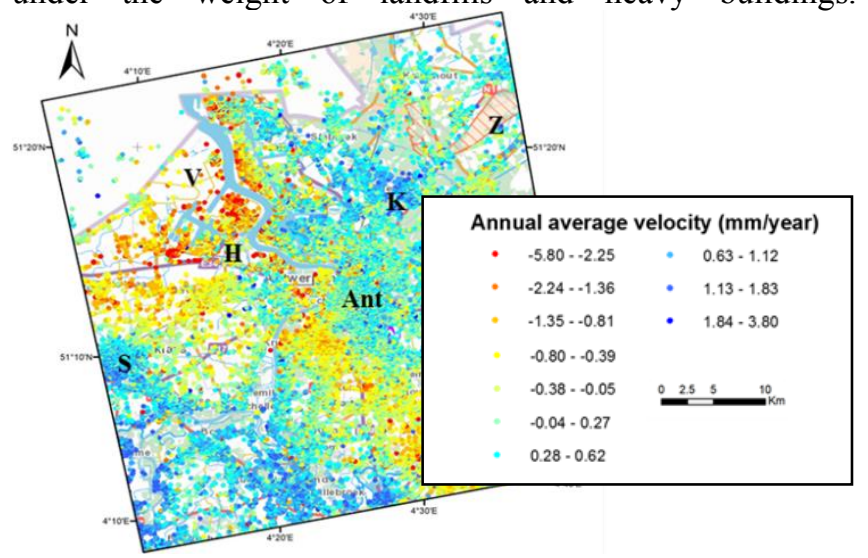

Figure 2: Colour classification based on the average annual velocity of PS points for SENTINEL 1 (2016-2020): (H) for harbour area, (Ant) (S) for Sint-Niklaas (K) for Kapellen, (V) Verdronken Land van Saeftinghe and (Z) De Zoom Kalmthoutse Heide.

\subsection{West Flanders Province}

At the Belgian western coast, a large subsidence bowl is visible since the ERS $1 / 2$ acquisitions in 1992. The Figure 3 shows the situation for the ENVISAT period as an example. The negative velocities are forming a subsidence bowl of 45 $\mathrm{km}$ long in the NW-SE direction and $25 \mathrm{~km}$ wide. The average annual negative velocity values range between -1 $\mathrm{mm} /$ year to $-2.9 \mathrm{~mm} /$ year. The groundwater piezometric levels (isohypses) of the Landenian aquifer (Tertiary) are superimposed on the velocities. The isohypses data were produced by the University of Gent using MODFLOW [11]. Formerly, this subsidence was partially mapped by A. Pissart and P. Lambot [12] by comparing two levelling periods realised by the NGI. The subsidence is caused by the groundwater overexploitation of the Landenian and Cambrian aquifers [11]. In addition to the groundwater overexploitation, the area located between Veurne and Ieper corresponds to the western coastal plain characterised by Holocene unconsolidated sediments. Therefore, this zone is prone to settlements due to the compressible nature of its sediments (clay, peat). 


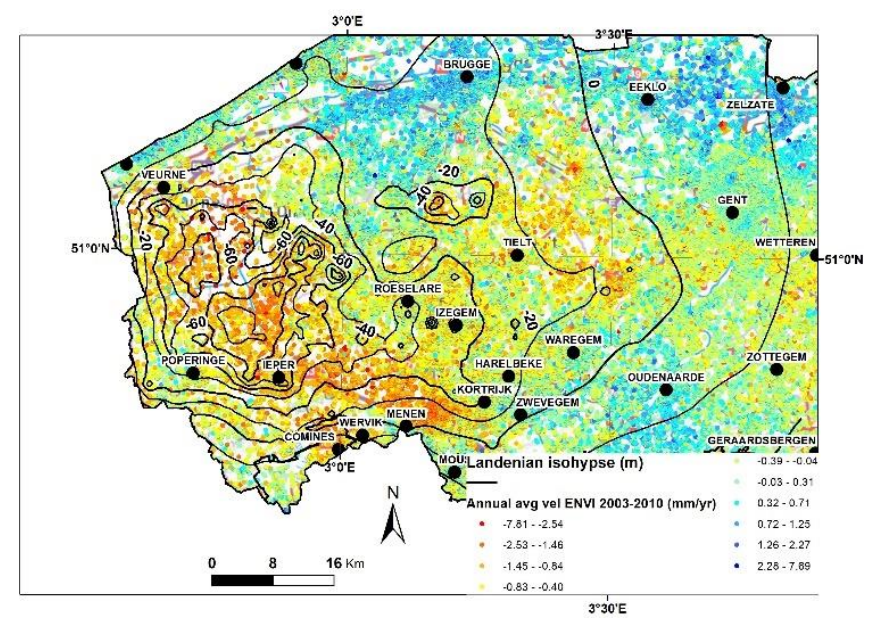

Figure 3: Isohypse of the groundwater level of the Landenian aquifer (m) and ENVISAT (2003-2010) annual average velocity $(\mathrm{mm} /$ year) in West Flanders.

\subsection{Merchtem area}

The processing results reveal a previously unknown subsidence/uplift area located in Belgium in the FlemishBrabant $25 \mathrm{Km} \mathrm{NW}$ of Brussels in Belgium (Figure 4). The ROI encompasses the cities of Aalst, Merchtem, Opwijk and Steenhuffel. The area prone to land subsidence amounts to $220 \mathrm{~km}^{2}$ during ERS and has been reduced drastically to 70 $\mathrm{km}^{2}$ during ENVISAT. Groundwater extractions mainly in the Cambro Silurian aquifers of the Paleozoic basement (HCOV 1300-1340) and partially in the Ledo-Paniselian aquifer (HCOV 600) for several breweries located in Merchtem, Steenhuffel and Londerzeel maintain a local land subsidence around these villages. Thanks to all the different satellites PS measurements, it was possible to follow the evolution of the ground deformations for three decades. The surface of this subsidence bowl was reduced with time while the surrounding cities like Aalst and recently in 2011 Opwijk were influenced by groundwater piezometric rebound inducing an uplift of the ground surface. This uplift indicates that the global rebound evolution of the piezometric levels of the region is influenced by the measures taken by the Flemish Region to reduce the impact of the groundwater overexploitation observed in the 1980's.

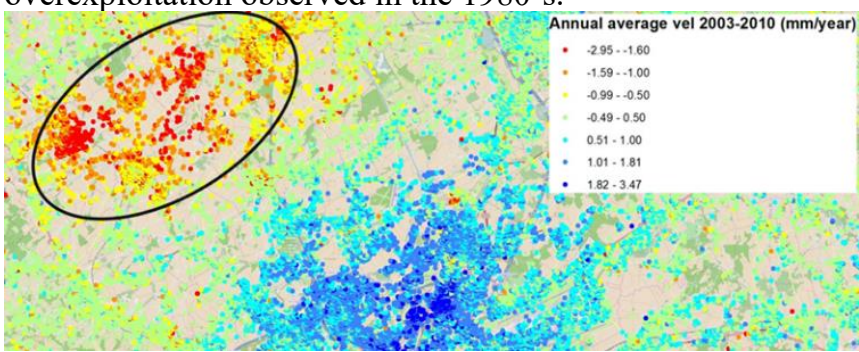

Figure 4: Colour classification based on the annual average velocities of the PS in the LOS direction for ENVISAT 20032010. The Merchtem area affected by land subsidence is delimited by the black ellipse.

\subsection{Coal mines}

The coals mines located in the Campine basin (Limburg, East of Belgium) are characterised during the ERS 1 / 2 period (1992-2001). The annual average LOS velocity values (Figure 5) are highlighting that the entire area belonging to the coal mine concessions is affected by two different trends. The western part is showing negative LOS velocities ranging from $-12 \mathrm{~mm} /$ year to $-0.5 \mathrm{~mm} /$ year while the eastern part is having positive LOS velocities up to $18.7 \mathrm{~mm} /$ year[13]. The spatial extension of the highest LOS velocities in absolute value is mainly limited to the borders of the defined coal concessions.

The analysis reveals that a part of the coal basin is affected by a land subsidence process related to the long mining activities in the past towards an uplifting [14]. The gradual rise of the water in the former workings is responsible for the observed uplift.

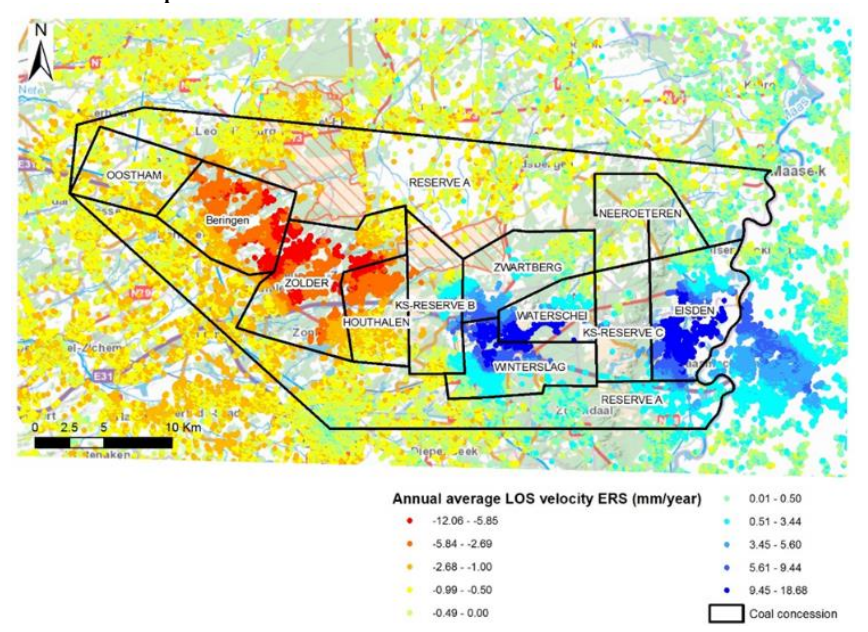

Figure 5 Colour classification based on the average annual velocities of PS points for ERS (1992-2001) and extension of the coal concessions in Limburg.

The coal extraction in the province of Hainaut (West of Belgium) exists since the antiquity. Although, the oldest reliable document mentioning coal extraction in Charleroi is a juridical document dated back to the $13^{\text {th }}$ century [15]. The beginning of the industrial development of the collieries started in the $18^{\text {th }}$ century with a net increase of the depth during the second half of the $19^{\text {th }}$ century. The last colliery closed in 1976. The Figure 6 shows the annual average velocity during the ENVISAT period on which the coal concessions are superimposed. From the west (blue) to the east (red) a global trend is still present and needs to be corrected in the future. Nevertheless, for most of the coal concessions, the PS velocities are positive and reached a maximum of $2.9 \mathrm{~mm} /$ year. In comparison with the ground movements recorded in Limburg the velocities are almost 10 times lower in this case but the rebound of the piezometric levels of the mining aquifer is responsible for the ground movements. The differences mainly reside in the time passed since the closure of the mines. In this case the last collieries 
closed 20 years before the last coal mine of Zolder in the Campine basin.

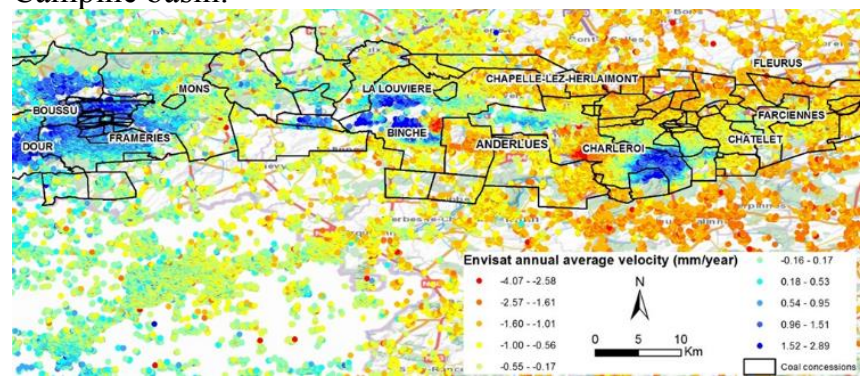

Figure 6: ENVISAT (2003-2010) annual average velocity (mm/year) above the Hainaut coal districts.

\section{CONCLUSION}

The PSInSAR technique can be used in Belgium to map and follow precisely qualitatively and quantitatively low amplitude land subsidence (eventually followed by an inelastic rebound) over a long period of time of \pm 30 years. Indeed, in Belgium, the so-called identified regional movements have average velocities of the order of a few $\mathrm{mm} /$ year. Only the Campine coal mining basin is characterized by velocities generally comprised between 10 $\mathrm{mm} /$ year to $20 \mathrm{~mm} / \mathrm{year}$. The cases presented here shows that land subsidence is related to groundwater pumping and especially overexploitation of aquifers for water production or associated to mining activities. In the case of Antwerp, compaction of Quaternary sediments is associated to a stress increase induced by industrial developments on unconsolidated sediments or landfills.

\section{ACKNOWLEDGEMENTS}

This research is funded under the Belgian Brain BELSPO program called LASUGEO (monitoring LAnd SUbsidence caused by Groundwater exploitation through gEOdetic measurements) and GEPATAR (GEotechnical and Patrimonial Archives Toolbox for ARchitectural conservation in Belgium). We would like to thank our colleague, Dr Jan Walstra, for the processing on the ERS SAR images made during the Brain GEPATAR project

\section{REFERENCES}

[1] C. Baeteman and A. Dassargues, Relations between the characteristics of deposits at major river mouths and their hydrogeological and geotechnical properties conditioning natural and man-induced land subsidence. Mémoires de l'Académie Royale des Sciences d'Outre-Mer, 1992. [Online]. Available: http://hdl.handle.net/2268/1973

[2] Q. Feng, G. Liu, L. Meng, E. Fu, H. Zhang, and K. Zhang, 'Land subsidence induced by groundwater extraction and building damage level assessment — a case study of Datun, China', Journal of China University of Mining and Technology, vol. 18 , no. 4, pp. 556-560, Dec. 2008, doi: 10.1016/S1006-1266(08)60293-X.
[3] T. Strozzi, U. Wegmuller, C. L. Werner, A. Wiesmann, and V. Spreckels, 'JERS SAR interferometry for land subsidence monitoring', IEEE Transactions on Geoscience and Remote Sensing, vol. 41, no. 7, pp. 1702-1708, Jul. 2003, doi: 10.1109/TGRS.2003.813273.

[4] F. Cigna et al., 'Monitoring land subsidence and its induced geological hazard with Synthetic Aperture Radar

Interferometry: A case study in Morelia, Mexico', Remote Sensing of Environment, vol. 117, pp. 146-161, Feb. 2012, doi: 10.1016/j.rse.2011.09.005.

[5] F. Cigna and D. Tapete, 'Present-day land subsidence rates, surface faulting hazard and risk in Mexico City with 20142020 Sentinel-1 IW InSAR', Remote Sensing of Environment, vol. 253, p. 112161, Feb. 2021, doi: 10.1016/j.rse.2020.112161.

[6] A. Ferretti, C. Prati, and F. Rocca, 'Permanent scatterers in SAR interferometry', IEEE Transactions on Geoscience and Remote Sensing, vol. 39, no. 1, pp. 8-20, Jan. 2001, doi: 10.1109/36.898661.

[7] A. Ferretti, C. Prati, and F. Rocca, 'Nonlinear subsidence rate estimation using permanent scatterers in differential SAR interferometry', IEEE Transactions on Geoscience and Remote Sensing, vol. 38, no. 5, pp. 2202-2212, Sep. 2000, doi: $10.1109 / 36.868878$.

[8] A. Hooper, 'A multi-temporal InSAR method incorporating both persistent scatterer and small baseline approaches', Geophysical Research Letters, vol. 35, no. 16, Aug. 2008, doi: 10.1029/2008GL034654.

[9] T. G. Farr et al., 'The shuttle radar topography mission', Reviews of geophysics, vol. 45, no. 2, 2007.

[10] P.-Y. Declercq, P. Gérard, E. Pirard, J. Walstra, and X. Devleeschouwer, 'Long-Term Subsidence Monitoring of the Alluvial Plain of the Scheldt River in Antwerp (Belgium) Using Radar Interferometry', Remote Sensing, vol. 13 , no. 6 , p. 1160, Mar. 2021, doi: 10.3390/rs13061160.

[11] M. Van Camp and K. Walraevens, 'Recovery scenarios for deep over-exploited aquifers with limited recharge: methodology and application to an aquifer in Belgium', Environmental Geology, vol. 56, no. 8, pp. 1505-1516, Feb. 2009, doi: 10.1007/s00254-008-1248-6.

[12] A. Pissart and P. Lambot, 'Les mouvements actuels du sol en Belgique; comparaison de deux nivellements IGN (19461948 et 1976-1980)', Annales de la Société géologique de Belgique, 1989.

[13] X. Devleeschouwer, M. Dusar, and P.-Y. Declercq, 'Ground motions revealed in the coal mining districts (Campine basin) using radar interferometry (PSInSAR technique).', VITO, Mol, Belgium, Jun. 2008, p. 6.

[14] A. Vervoort and P.-Y. Declercq, 'Upward surface movement above deep coal mines after closure and flooding of underground workings', International Journal of Mining Science and Technology, 2017.

[15] G. Arnould, Bassin houiller du couchant de Mons: mémoire historique et descriptif. Manceaux, 1877. 